\title{
Resenha
}

\section{Financiamento da Educação básica no Brasil}

\author{
Wellington Ferreira de Jesus \\ Universidade Católica de Brasília \\ Secretaria de Educação do Distrito Federal
}

AMARAL, Nelson Cardoso do. Para compreender o financiamento da educação básica no Brasil. Brasília: Liber Livro, 2012.

A temática do financiamento da educação no Brasil, sobretudo da educação básica, tem assumido centralidade nos estudos, pesquisas, trabalhos, dissertações, teses e mesmo nos cursos referentes à Educação ou Ciências Humanas e Sociais, particularmente a partir da década de 1990, com as reformas educacionais conduzidas pelo Estado. Pensar educação é, significativamente, refletir também sobre os aportes, a alocação e a redistribuição de recursos. E esse processo de reflexão deve ocorrer num contexto interdisciplinar, haja vista o fato de que questões de ordem histórica, política, institucional, de arenas decisórias e prioridades, entre outras, interconectam-se e se intercruzam nessa discussão.

Estudar e analisar o financiamento da educação no Brasil é também discutir - contexto da dívida histórica, é propor reflexões sobre a necessidade do controle social de recursos e da prioridade das políticas públicas. É propondo pensar nessas e em outras questões que a obra de Nelson Cardoso do Amaral deve ser recebida por todas e todos que, de maneira mais ou menos próxima, procuram conhecer, estudar, aprofundar-se ou buscar um livro que estabeleça, em perspectiva interdisciplinar, as reflexões sobre o financiamento da educação básica brasileira.

Lançado em um momento histórico oportuno, em que a sociedade terá condições de debater o Plano Nacional de Educação, estabelecendo objetivos, metas e diretrizes para a educação brasileira na próxima década (PNE 2012-2021), o livro é dividido em seis capítulos, didaticamente organizados. Ao final de cada capítulo, há indicações de leituras complementares, de sítios na rede mundial de computadores, além da apresentação de questões para reflexão e para pesquisas que podem promover o aprofundamento sobre a tema abordado. Por fim, o leitor encontra uma síntese - sempre bem-vinda - das principais ideias do capítulo.

0 primeiro capítulo situa o leitor na esfera legal-institucional, discutindo o financiamento da educação conforme a Constituição Federal (CF) de 1988. Destaca-se nesse capítulo a discussão acerca da problemática entre o que de fato 
é previsto na CF e as contradições de sua interpretação. Ao mesmo tempo, há uma reflexão sobre a proteção de recursos, a denominada vinculação de verbas, a qual o autor afirma ser uma tripla vinculação: dos impostos, do percentual do Produto Interno Bruto (PIB) e do salário educação. Na sequência, é feita uma discussão histórica que opõe os economistas da "área social", que defendem maior aporte de recursos para os setores sociais - no caso, o setor educacional - aos economistas da "área econômica", os quais propugnam que há recursos em suficiência e que o problema estaria na gestão desses recursos. É interessante refletir sobre o pensamento de Nelson Cardoso do Amaral ao final do primeiro capítulo, em que o autor destaca a necessidade de argumentos corretos e justos no sentido de ampliação dos recursos destinados à educação básica no Brasil.

O segundo capítulo, na perspectiva interdisciplinar em que o livro é construído, discute um tema que desde a década de 1930 tem sido o cerne dos debates sobre educação no Brasil: o "desafio" do sistema educacional brasileiro. Nas primeiras décadas do século $X X$, os renovadores instigavam o debate sobre "o problema nacional", a construção de um sistema nacional articulado e com suficiência de recursos para todo o País. Esse debate, ao longo do século XX, foi compreendido como a "dívida histórica". Em outras palavras, buscava-se identificar uma forma de promover educação de qualidade social para a maior parcela da população brasileira, sintomaticamente a parcela mais vulnerável. É esse o "tamanho do desafio" da educação básica brasileira que, com riqueza de dados estatísticos, Nelson Cardoso se "desafia" a discutir, observando que a ampliação da população em idade escolar, no caso específico da educação básica, não se fez acompanhar de uma ampliação proporcional de recursos, já que, "amparados" na Constituição Federal, muitos governantes transformam o "piso em teto".

0 terceiro capítulo pode ser considerado como uma espécie de sistema cardiorrespiratório da obra, pois nele os leitores encontram a dinâmica, a mecânica, as contradições, os mecanismos de financiamento e o papel dos impostos e do salário-educação para a alocação de recursos. Nesse sentido, o livro - ricamente ilustrado com tabelas e gráficos - demonstra os valores e os percentuais alocados, estabelece comparações e levanta questões instigantes, como, por exemplo, o percentual do PIB como referência para o financiamento da educação no País.

O quarto capítulo constitui-se em verdadeira aula de pesquisa e análise de dados estatísticos. 0 autor apresenta um rico conjunto de dados sobre o financiamento da educação básica no período de pouco mais uma década (de 1997 a 2009). Esse período representou o momento histórico das reformas educacionais situadas na perspectiva da reforma do Estado que caracterizou o governo Fernando Henrique Cardoso (FHC) e, de certa forma, a gestão de Luís Inácio Lula da Silva (2003-2010), que manteve muitos dos elementos propostos pelo governo anterior. Recorde-se que, entre outros aspectos, os vetos aos artigos que implicavam ampliação de recursos no PNE 2001-2010, aplicados na gestão FHC, foram mantidos durante o governo Lula. Entretanto, o cerne deste capítulo é fornecer o aporte de informações 
para a discussão dos fundos constitucionais especiais destinados à educação básica, o Fundef (1997-2006) e o Fundeb (2006-2020).

0 quinto capítulo constitui, certamente, o centro do trabalho. Se anteriormente se comparou o capítulo três ao sistema cardiorrespiratório, temos aqui o cérebro da obra. Neste capítulo, o autor explica os mecanismos do Fundef, como política focalizada no ensino fundamental, e do Fundeb, com a ampliação dos recursos a toda a educação básica brasileira. Nesse sentido, Nelson Cardoso retoma a história da educação (ou dívida histórica com esse setor), relembrando Anísio Teixeira, um dos "pioneiros" da década de 1930, que já esboçara, no início do século passado, a visão sobre a necessidade de criação um fundo específico para o financiamento da "instrução elementar". Nesse esforço interdisciplinar, o livro aponta questões e contradições significativas que emergiram a partir do Fundef e do Fundeb; entre elas, a redistribuição dos recursos, a complementação da União, o papel dos impostos, as limitações e as especificidades de cada fundo, além dos mecanismos de controle social. Ousaríamos lançar outra questão: estaríamos, com os fundos constitucionais de financiamento da educação básica, frente à primeira política de Estado da educação brasileira em mais de meio século de história? Embora ainda estejamos no centro de um processo histórico, os dados apresentados por Nelson Cardoso do Amaral parecem nos aproximar dessa resposta, e de forma positiva.

O sexto capítulo - O financiamento da educação com qualidade: o Brasil possui condições para um salto educacional? - é revelador das angústias, das contradições, dos limites e das possibilidades que esta temática, financiamento da educação, representa para os pesquisadores nos trabalhos que desenvolvem. Sabendo que "qualidade" é um termo polissêmico e, no que tange às políticas públicas, deve ser necessariamente adjetivado, o autor nos leva a considerar a preocupação com uma "qualidade social" que permita se pensar a educação básica como um dos elementos constitutivos da transformação da realidade histórica e social, ou, em outras palavras, um "resgate da dívida histórica". Nesse sentido, são analisadas temáticas que se entrelaçam para uma compreensão ampliada do financiamento da educação, quais sejam: impactos do percentual do PIB investido na educação em relação à evolução demográfica da população brasileira; custo-alunoqualidade e custo-aluno-qualidade-inicial; as proposições de investimentos no contexto do novo PNE (2011-2020) e, de forma significativa, o que representa o "salto educacional" no Brasil. Não basta comparar os resultados nacionais com os índices internacionais; importa, sobretudo, o esforço do poder público e da sociedade no sentido de estabelecer tanto parâmetros quanto objetivos e metas para o "salto educacional" brasileiro, com qualidade social.

Nelson Cardoso do Amaral, profissional zeloso, pesquisador de elevado cabedal e profundo conhecedor da temática do financiamento, dedica sua obra aos alunos de graduação e pós-graduação, futuras professoras e futuros professores do Brasil. Contudo, considerando a organização, a escrita primorosa e a qualidade dos dados, recomendamos a obra a todas e a todos que desejam compreender e 
discutir a dinâmica do financiamento da educação no Brasil, refletir sobre essa dinâmica e dela participar de forma mais crítica. A obra deve ser dedicada também às brasileiras e aos brasileiros que, de uma ou de outra forma, buscam superar a "dívida histórica" com a educação, sobretudo com a educação básica do País, algo que Nelson Cardoso do Amaral nos ensina com maestria.

Recebido em maio de 2012

Aceito em julho de 2012

Wellington Ferreira de Jesus é doutor em Educação pela Universidade Federal de Goiás. Professor da Secretaria de Educação do Distrito Federal, da graduação e do Programa de Pós- Graduação em Educação da Universidade Católica de Brasília. Publicação recente: Email: wellington.jesusdacatolica.edu.br 